\title{
WestVirginiaUniversity
}

THE RESEARCH REPOSITORY @ WVU

Graduate Theses, Dissertations, and Problem Reports

2001

\section{Parent-infant interactions during acute painful procedures}

Catherine Bradford McClellan

West Virginia University

Follow this and additional works at: https://researchrepository.wvu.edu/etd

\section{Recommended Citation}

McClellan, Catherine Bradford, "Parent-infant interactions during acute painful procedures" (2001). Graduate Theses, Dissertations, and Problem Reports. 715.

https://researchrepository.wvu.edu/etd/715

This Thesis is protected by copyright and/or related rights. It has been brought to you by the The Research Repository @ WVU with permission from the rights-holder(s). You are free to use this Thesis in any way that is permitted by the copyright and related rights legislation that applies to your use. For other uses you must obtain permission from the rights-holder(s) directly, unless additional rights are indicated by a Creative Commons license in the record and/ or on the work itself. This Thesis has been accepted for inclusion in WVU Graduate Theses, Dissertations, and Problem Reports collection by an authorized administrator of The Research Repository @ WVU. For more information, please contact researchrepository@mail.wvu.edu. 
Parent-Infant Interactions During Acute Painful Procedures

Catherine B. McClellan

Thesis submitted to the College of Arts and Sciences at

West Virginia University in partial fulfillment

of the requirements for the degree of

\author{
Master of Arts \\ in \\ Psychology
}

\author{
Lindsey L. Cohen, Ph.D., Chair \\ Christina D. Adams, Ph.D. \\ Cynthia Anderson, Ph.D. \\ Department of Psychology
}

Morgantown, West Virginia

2001

Keyword: Pediatric Pain, Immunizations, Parent-Child Interactions 


\section{Abstract \\ Parent-Infant Interactions During Acute Painful Procedures \\ Catherine B. McClellan}

Despite the current recognition of infant procedural pain and distress, there is a dearth of research, both in the assessment and treatment literature, of infant procedural distress. This study examined how specific parent behaviors relate to infant procedural distress and whether this relation is mediated by birth order. Results indicated that that females were rated as more distressed than were males, and that birth order did not prove to be a distinguishing factor in infant distress. Finally, while some behaviors appear to have a similar influence on both preschoolers' and infants' behaviors, parents' behavior during infants' distressing procedures were found to be dissimilar to those of parents' behavior during preschoolers' distressing procedures. 


\section{Acknowledgements}

I would like to acknowledge first and foremost, Dr. Lindsey Lewis Cohen, an ideal advisor and friend, without whom this thesis would not have been possible. I would like to thank my thesis committee members, Dr. Christina D. Adams and Dr. Cynthia Anderson for their thoughtful comments and suggestions. I would also like to thank Dr. JoNell Strough and Dr. Stan Cohen for help with statistical analyses. I would like to thank Katie Chiasson and Nicki Salvey for their excellent help in reliably coding many screaming babies.

I would also like to thank my wonderful husband, Joshua Benji Fisher, and my family for their support and encouragement, Cindy H. Bougard for providing me with the key motivational factor to finish the thesis, and Rebecca S. Bernard for keeping my spirits up! 
Table of Contents

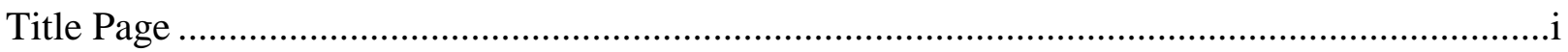

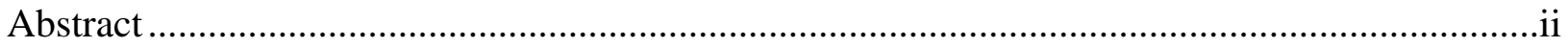

Acknowledgements ............................................................................................................



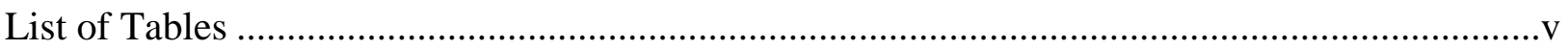

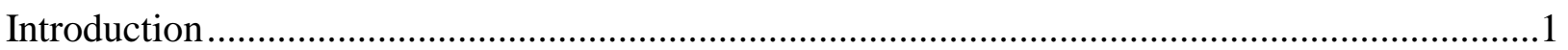

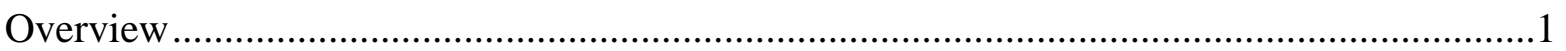

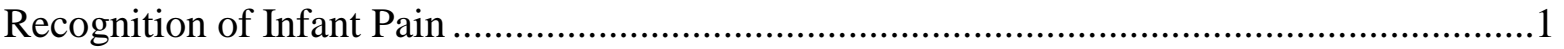

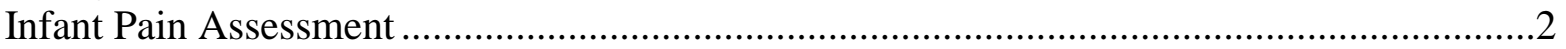

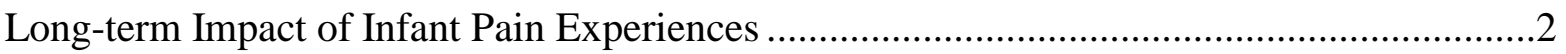

Treatment of Infant Pain .........................................................................................

Assessment of Preschoolers' Pain .................................................................................

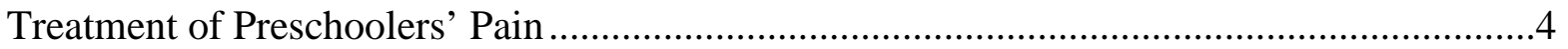

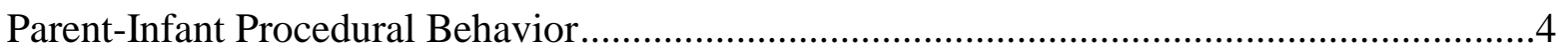

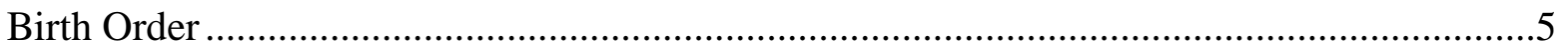

Birth Order in Pediatric Settings .........................................................................................





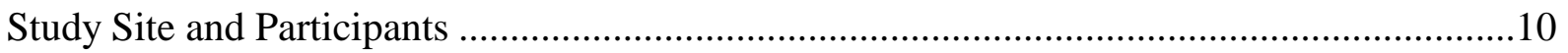



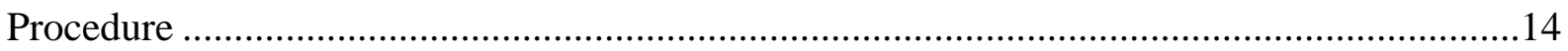

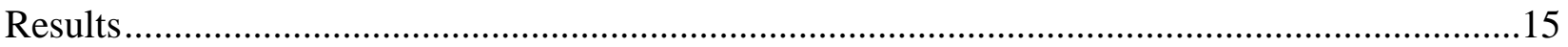

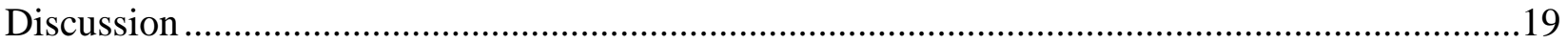

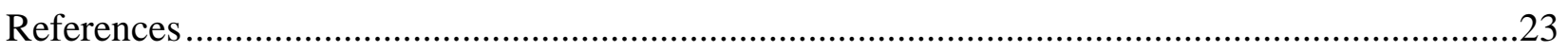

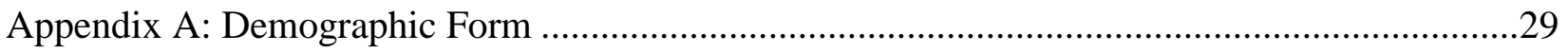

Appendix B: Parent Post-Shot Questionnaire ......................................................................

Appendix C: Nurse Post-Shot Questionnaire ………………......................................................31

Appendix D: Measure of Adult and Infant Soothing and Distress (MAISD) Coding Manual.......32

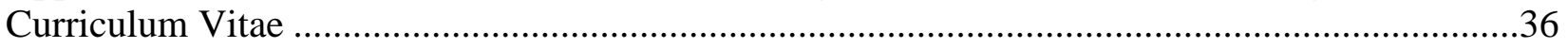


List of Tables

Table 1 11

Table 2

Table 3

16

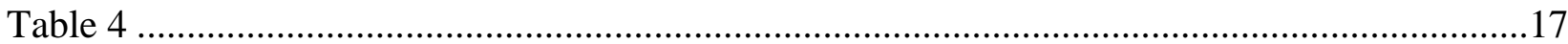

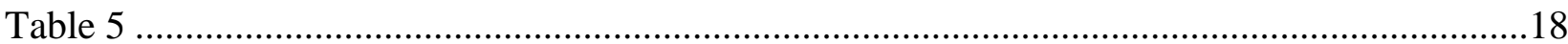


Parent-Infant Interactions During Acute Painful Procedures

\section{Overview}

Pediatric psychology research has the broadly defined goal of understanding the psychological aspects involved in children's medical health care. One particularly important area of study within the field of pediatric psychology is medical procedural distress. Researchers and clinicians alike are keenly interested in how they can reduce the distress that infants and children experience during medical procedures. Research (Blount et al. 1989) investigating children's procedural distress has highlighted the importance of parent behavior as a mediating factor in children's experience of painful procedures. Because of practical limitations in our ability to study infants' pain experiences (e.g., lack of self-report), and the historical neglect of infant pain, little is known about how infants experience procedural pain. This study will examine the role of parent behavior in predicting infant distress during painful medical procedures. The guiding questions include whether specific parent behaviors are associated with infant distress, and whether previous parenting experience is related to these behaviors.

\section{Recognition of Infant Pain}

Research on procedural pain in infants historically has been ignored, both in the assessment and treatment literature (Anand \& McGrath, 1993a). In addition, clinical pain management for infants has been inadequate (Porter, Wolf, Gold, Lotsoff, \& Miller, 1997), particularly when compared to treatment of pain for older children and adults (Anand \& McGrath 1993a; Walco, Cassidy, \& Schechter 1994). Several explanations may account the lack of research and clinical focus on pain management for infants. First, there has been a misconception that infants' neural immaturity will shield them from experiencing pain (McLaughlin, Hull, Edwards, Cramer, \& Dewey, 1993). Second, infants' inability to verbally describe pain results in their pain not being well addressed (Schechter, Berde, \& Yaster, 1993). Third, it has been argued that the risks involved with the use of analgesics with infants outweigh the benefits of pain reduction (Hatch, 1987). Last, early post-natal pain experiences have been viewed as having no negative impacts on future behavior or development because people do not recall these experiences (Swafford \& Allen, 1968; Zimmerman \& Torey, 1965). Along with these beliefs, infant pain traditionally has been poorly managed. For example, physicians and nurses report that even for painful procedures (such as insertion of chest tubes), analgesics and comfort measures are rarely used with infants (Porter et al., 1977). Finley, McGrath, Forward, McNeil, and Fitzgerald (1996) conducted a study investigating parents' management of their children's pain following pediatric surgery. They found that even in cases where parents recognized their children's pain, most parents did not provide their children with sufficient doses of medication for pain control.

A recent surge of studies re-examining infant procedural pain have challenged these beliefs. Porter and colleagues (1997) investigated the perceptions of pediatric nurses and physicians regarding how much pain infants typically feel during a variety of painful procedures. Most participants indicated that they believe infants experience pain that is 
equivalent to or greater than the pain experienced by adults. Further, recent research has demonstrated that even premature infants can distinguish, both behaviorally and physiologically, between "sham" and real heelsticks (Johnston, Stevens, Yang, \& Horton, 1995). Several other researchers have begun to produce data indicating that infants experience pain in a similar manner and magnitude to adults (Anand \& Hickey, 1987; Fitzgerald, 1991; Fitzgerald \& Anand 1993; Fitzgerald \& Andrews, 1996). Last, health care professionals are acknowledging that pain relief benefits generally outweigh risks with analgesics (Porter, Grunau, \& Anand, 1999).

\section{Infant Pain Assessment}

Paralleling research indicating that infants experience pain, valid and reliable infant pain assessment tools have begun to emerge in the literature (Attia, Amiel-Tison, \& Mayer, 1987; Clancy, Anand, \& Lally, 1992; Lawrence et al., 1993; Mathews, McGrath, \& Pigeon, 1993). Infant distress currently is assessed in a variety of fashions, such as with physiological indexes and behavioral measures. Some physiological measures of distress are heart rate, blood pressure, respiratory rate, and sweating (for review, see Chapter 5, Finley \& McGrath, 1998). Heart rate is a particularly useful physiological measure of pain because of its practicality; not only is heart rate relatively easy to obtain, but it also is relatively easy to train individuals to measure it reliably and accurately. Several researchers have demonstrated that infant heart rate generally increases during painful experiences such as a heal lance and that increased heart rate tends to covary with crying (Craig, Whitfield, Grunau, Linton, \& Hakjistavropoulos, 1993; Owens, \& Todt, 1984).

Observational measures also are useful in assessing infant distress. Researchers have found that nurses' decisions to medicate their pediatric patients are based in part on nurses' observations of children's behaviors (Burokas, 1984). One important component of infant distress is infant's facial distress. Huebner and Izard (1988) sought to understand how mothers respond to varying levels of infants' facial affective distress. They concluded that mothers were able to discriminate infants' discrete facial expressions and that parents were accurate in rating physical distress expressions. Several observational scales have been developed to assess overt infant distress. These instruments are typically completed by coding videotapes of the medical procedure and include careful examination of infant distress as evidenced by changes in the child's cry, facial expression, and body position (for review, see Chapter 6, Finely \& McGrath, 1998).

\section{Long-term Impact of Infant Pain Experiences}

In addition to the increased awareness that infants experience procedural pain and distress, there is growing evidence that these early pain experiences have detrimental effects on infant health and development. In a study investigating the impact of pain treatment in infant circumcisions, Taddio, Katz, Ilersich, and Koren (1997) found that infants who received topical anesthesia for circumcision, as compared to those who did not receive the anesthesia, demonstrated lower levels of distress during later routine immunizations. Others have corroborated this finding and suggested that early pain experiences result in increased reactivity and sensitivity to later painful experiences (Fitzgerald, Millard, \& McIntosh, 1989; Gunnar, Porter, Wolf, Rigatuso, \& Larson, 1995). In a review article of animal and human research in this area, Porter, Grunau, and Anand (1999) concluded that poorly managed pain 
could have a harmful influence on infants' immediate and future coping abilities, as well as reactions to and perceptions of pain.

\section{Treatment of Infant Pain}

In response to the research documenting that infants experience procedural pain and that there might be long-term negative implications, a handful of studies have examined methods for reducing infant procedural pain and distress. For example, Johnston and colleagues (1997) examined the effectiveness of rocking (infant placed on an undulating air mattress prior to heel lancing) and sucrose (sugar-water dispensed onto the infant's tongue just prior to heel lancing) in reducing pre-term infants' pain and distress during heel lancing procedures. In their study, they included four conditions: rocking, sucrose, a combination of rocking and sucrose, and a placebo condition (water placed onto the infant's tongue just prior to heal lancing). They found that pre-term infants who received sucrose alone or sucrose and rocking combined demonstrated less of a behavioral reaction to the heel lancing. Other researchers (Taddio, Nulman, Goldback, Ipp, \& Koren, 1994) investigated the effectiveness of topical anesthetic (EMLA) in reducing infant distress during routine immunizations. They found that the infants treated with the EMLA prior to immunization exhibited less distress and cried for shorter periods of time than did the infants who did not receive the EMLA. Although several treatments have received empirical support, they do not appear to have been guided by a thorough assessment of the correlates of infant distress. In fact, there is a dearth of research assessing the covariates of infant procedural distress. This line of inquiry is essential to build the assessment base that will guide the development of effective distress management interventions (Blount, Bunke, \& Zaff, 2000). For example, by identifying the specific parent behaviors that reduce or increase infant distress, researchers will be able to develop comprehensive treatments and recommendations to reduce infant procedural distress.

\section{Assessment of Preschoolers' Pain}

Whereas there are few studies assessing correlates of infant procedural distress, there is ample research on this topic involving preschoolers and older children. For example, Jacobsen and colleagues (1990) examined various factors that impact child distress during venipuncture. The researchers found that higher child distress was related to being younger, having fewer previous venipuncture experiences, and having poorer venous access. In addition, high parent anxiety and parent expectation of poor child cooperation have been shown to predict high child distress. Broome and Endsley (1989) found that children who had mothers who rated their children as highly anxious before the procedure were more likely to be distressed and less likely to be cooperative during the immunization. Additionally, they found that maternal ratings of self and child anxiety were positively correlated.

Specific parent behaviors have been identified as being strong predictors of child procedural distress. For instance, adult (parent and staff) reassuring, empathetic, apologetic, critical, and giving child control behaviors predict heightened child procedural distress behavior (Blount et al., 1989; Blount, Landolf-Fritsche, Powers, \& Sturges, 1991). In contrast, adult non-procedural talk (e.g. distraction) and commands to cope correlate positively with child coping behaviors (Frank, Blount, Smith, Manimala, \& Martin, 1995). 
Manne and colleagues (1992) also investigated parent child interactions during invasive medical procedures to determine which parent behaviors promoted child coping and reduced child distress. The researchers found that parents who engaged in distraction were able to reduce their child's distress, yet other parent behaviors (including praise and direct commands to cope) increased child distress. Other researchers (e.g., Cohen, Blount, Cohen, Schaen, \& Zaff, 1999; Dahlquist et al., 1994) have found similar findings regarding the effectiveness of distraction in reducing distress. Dahlquist and colleagues also found that parents' use of poor discipline strategies (such as being less nurturing, less organized, and less consistent) was related to greater child anticipatory distress.

\section{Treatment of Preschoolers' Pain}

Based on assessment studies, treatment research has targeted parent behaviors to reduce procedural distress in the preschool age and older child. In Powers' 1999 review of 13 pediatric treatment outcome studies, eight studies included some form of parent training to aid children (none of these studies targeted populations of infants) in coping with acute painful procedures ranging from venipuncture (Manne et al., 1990) to bone marrow aspirations (Jay, Elliott, Ozolins, Olson, \& Pruitt, 1985). Blount and colleagues (1994) were able to reduce patient distress during bone marrow aspiration and lumbar punctures by having the children rehearse their distraction technique prior to the procedure and by training parents to distract and encourage coping in their child. Similarly, Cohen, Blount, and Panopoulos (1997) trained nurses to engage in distracting behaviors, (i.e., encouraging the child to attend to a movie), which resulted in decreased child distress during immunizations. Practically all of these successful treatment outcome studies were based on the solid assessment findings (e.g., Blount et al, 1989; Frank et al., 1995) with preschoolers' and older children's procedural distress.

\section{Parent-Infant Procedural Behavior}

Although the assessment of parent behavior during children's procedures has been critical to the pediatric pain management field, only two studies have examined parent behavior during infants' painful medical procedures. This lack of research is especially alarming because infants are almost entirely dependent upon their parents for soothing when distressed (Kagan, 1994). Further, research in other areas of child development have found that maternal responsiveness to infant distress is central to infant development (Watson, 1966, 1985), attachment (Ainsworth, Blehar, Waters, \& Wall, 1978), and distress at later points in infancy (Bell \& Ainsworth, 1972).

Lewis and Ramsay (1999) examined whether maternal soothing impacted infant everyday and procedural distress. The researchers conducted two studies. In the first study, infants were observed during an immunization. In the second study infants were observed during non-injection distress occurring in the medical room (e.g., during a diaper change) and also during injection distress. For both studies, infant distress was investigated longitudinally (at 2, 4, and 6 months) with physiological (i.e., cortisol elevations) and behavioral (distress scores based upon videotaped observations of the infant) measures. Neither of the studies demonstrated significant correlations between infant distress and maternal soothing. Lewis and Ramsay concluded that maternal soothing is unrelated to infant procedural distress. A limitation of this study is that the authors did not code discrete parent behavior (e.g., reassuring comments) as had been done in the preschooler literature. Instead, maternal 
behaviors were combined into a single, quantitative category (none, low, moderate, or high soothing). It is possible that helpful (e.g., distraction) and detrimental (e.g., reassurance) behaviors could have canceled each other out in analyses. Additionally, the authors may have decreased the power of their study by categorizing parents' behavior rather than examining behaviors as continuous data.

Sweet and McGrath (1998) recognized the importance of relating specific adult behaviors to infant distress. As such, they investigated the association of maternal behaviors on infants' distress during immunization. Due to the lack of a behavioral measure assessing adults' behavior during infants' procedure, Sweet and McGrath used the Child-Adult Medical Procedure Interaction Scale (CAMPIS; Blount et al., 1989). Consistent with the literature with populations of preschoolers and older children (e.g. Blount et al., 1989), Sweet and McGrath found that mothers' reassurance predicted infant distress. Other maternal behaviors that were positively related to infant distress were apologies, empathetic statements, and criticism. Sweet and McGrath also found that no maternal behavior was associated with infant coping. This finding is inconsistent with research that has demonstrated positive relations between maternal distraction and commands to engage in coping behaviors and preschool child coping behaviors (Blount et al., 1989; Blount et al., 1991; Frank et al., 1995). Sweet and McGrath acknowledged that the CAMPIS does not adequately assess infant and adult behavior during infants' procedures. Specifically, the CAMPIS was developed as a scale coding verbal behavior of preschoolers and older children from audiotape rather than videotape of the procedure. Behaviors assessed by the CAMPIS such as non-procedural talk, verbal fear, information seeking, and requests for emotional support, might not be appropriate for infants. Similarly, parents' verbal reassurance, checking on the child's status, and notifying the child of the procedure to come, would likely be low in frequency with this population. In addition, the CAMPIS does not assess adult behavior that might be more common with infants. For example, rocking, providing a pacifier, and nursing the child are common adult behaviors employed to soothe distressed infants.

\section{Birth Order}

There are only two studies examining the relation between parent behavior and infant procedural distress, and almost no studies assessing other correlates of infant procedural distress, yet there are studies that have addressed correlates of infant non-procedural distress. A review of this literature revealed the importance of considering the relations among birth order, parent behavior, and infant distress.

In terms of the relation between parental behavior and birth order, a number of studies suggest that first-borns receive more maternal attention than later-borns. For example, Belsky, Gilstrap, and Rovine (1984) examined the stability and change of parent-infant interactions at 1, 3, and 9 months of age. They found that at all three measurement periods, first-born infants consistently received more parental attention than did later-borns.

Extending this to parent behavior during infants' medical procedures, it might be expected that parents of first-borns will engage in more attention or greater quantities of overall parent-child interaction than parents of later-borns.

Donate-Bartfield and Passman (1985) considered the role of birth order and parental responsiveness by studying how parents responded to a cry that they believed was coming 
from their infant. They found that both mothers and fathers of first-born infants responded more quickly and frequently to cries that they believed were coming from their infants than did the parents of later born infants. Although parents of first-borns were more responsive than parents of later-borns, the authors did not examine whether they were more effective at soothing their infants. Consistent with other studies in the birth order literature, parents of first-borns might be more responsive and attentive to infant distress during medical procedures.

Lewis and Kreitzberg (1979) investigated the role of birth order in mother-infant interactions by observing mothers and their 3-month-old infants during a 2-hour period at their homes. The researchers found that the frequency of the mothers' vocalizations significantly decreased as birth order increased, such that mothers spoke the most to firstborns, and that for almost all behaviors (such as play, kiss, and smile), mothers engaged significantly more with first-borns. Infant behavior also was found to vary significantly as a result of birth order; first-borns vocalized, smiled, laughed, played with objects, and looked at their mothers more frequently than did later-borns. Although Lewis and Kreitzberg did not examine infant distress behaviors, the findings do indicate that parent behavior varies by birth order, which in turn is related to infant behavior.

Other research has found similar patterns of parent-infant interaction differences directly related to birth order of the child. Bakeman and Brown (1977) found that parents of first-borns were more likely to initiate behavior with their infants and attended more to their infants. One would assume that increased attending and quantity of interactions would necessarily be positive; however in this study, the first-born infants required longer feeding times and took more effort to achieve a calm state. In other words, the greater quantity of parent behaviors might reflect the less effective and efficient nature of the first-time mothers' parenting behaviors. Thus, it might be that parents of first-born infants are not as efficient at soothing their distressed infants as parents of later-borns.

\section{Birth Order in Pediatric Settings}

Other pediatric studies have indicated that parents provide an increased amount of attention and time to their first-born infants. Cohen and Beckwith (1977) sought to investigate whether the expected pattern of increased attention to first-borns is altered when the children under investigation are pre-term babies, who typically require more care. The researchers conducted in-home observations of parents and their infants for a period of one sleep-wake cycle of 1-, 3-, and 8-month-old infants. Whereas the researchers found no birth order effects at 1 month of age, by 3 months the first-born infants were receiving more maternal attentiveness, such as holding and responding to the infant's distress. By 8 months of age, infants were receiving more maternal attentiveness in addition to more regular attentiveness from others as compared to later-borns. Extending these findings to pediatric procedural distress, it might be expected that first-borns would receive more attention during distressing medical events.

Birth order has also been shown to impact the interactions of parents with their older children during medical procedures. Fielding and Tam (1990) examined the parent-child interactions of 2- to 10-year-old children who were hospitalized for minor elective surgery. The authors investigated maternal and child procedural distress, parent-child interaction style 
(caretaking, comforting, or play), whether child or parent initiated the interaction, degree of physical comfort, and demographic information including the target child's birth order. The authors found that birth order of the child was a significant predictor of mother-child interaction, with first-born children participating in more interaction with their parents than later-born children. They also found that first-born children tended to have higher initial levels of distress than did later born children. Based on these findings, it might be that firstborn infants, as compared to later-born infants, display higher distress and also engage in more interaction with their parents during medical procedures.

Only a handful of studies have examined parent behavior, birth order, and infant distress in medical situations. For example, Bendersky and Lewis (1986) sought to determine how birth order, pre-term birth, and at risk status at birth impact maternal interactive behavior. Whereas low-risk infants' birth order did not influence mothers' behavior, the researchers found that mothers were more responsive (note: in this study responsiveness was evaluated quantitatively and not qualitatively) to first-born high-risk infants than to later-born high-risk infants. The authors suggested that parents' perceptions of first-versus later-born children differ because of previous parenting experience. For example, mothers may be able to more efficiently interpret their second-born infant's cry of distress after years of previous experience parenting their first-born infants. Applying these findings to infants' medical procedures, parents of first-born infants may devote more time and energy to their infant's distress, but they might lack parenting experience. Thus, it might be expected that parents of later-born infants would be more efficient at soothing their infants.

In their study of the impact of birth order on mother-infant feeding interactions, Thoman, Turner, Leiderman, and Barnett (1970) found that mothers of first-born infants spent more time bottle feeding their infants then mothers of later born infants. However, despite the increased time spent feeding their infants, the first-born infants consumed less formula than later born infants. Similar to the findings of Bakeman and Brown (1977), parents' additional engagement with their child did not necessarily result in nutritional benefits for the child. Extending these results to infants' pain experiences, it might be that parents of first-borns engage in more but less effective soothing behaviors than parents of later-borns.

\section{Summary and Purpose of Study}

In summary, the historical neglect of infant procedural distress is likely due to misconceptions about infants' abilities to experience pain (McLaughlin et al., 1993), concerns about side effects of pain medication (Hatch, 1987), a lack of assessment measures for infant pain (Schechter et al., 1993), and a belief that early pain experiences would not have any long term impact (Swafford \& Allen, 1968). Recent studies have challenged these beliefs and suggest that infants experience pain in similar magnitudes to older individuals (Johnston et al., 1995; Porter et al., 1997), some new analgesics are proving to be safe (e.g., EMLA, Taddio et al., 1997), adequate infant pain assessment tools have been developed (for review, see Finely \& McGrath, 1998), and researchers have demonstrated that infants can experience long-term negative impacts from early pain experiences (Fitzgerald et al., 1996; Gunnar et al., 1995; Taddio et al., 1997). Although researchers are beginning to devote more time and energy to treating infant pain (e.g., Johnston et al., 1997; Taddio et al., 1994), very 
few of the prerequisite assessment studies have been conducted to describe the correlates of infant procedural distress.

Parent behavior has been determined to play a significant mediating role in pre-school age children's experience of procedural distress (e.g., Blount et al., 1989; Frank et al., 1995), however the only infant studies of this relation (Lewis \& Ramsay, 1999; Sweet \& McGrath, 1998) are limited by inadequate assessment of parent behavior. Specifically, Lewis and Ramsey failed to assess specific parent behaviors, such as those that have been shown to predict preschooler distress and coping (e.g., reassurance and distraction), and Sweet and McGrath used a verbal behavior scale developed for preschoolers' procedures that failed to assess nonverbal behaviors (e.g., rocking, providing a pacifier) relevant to infants.

The infant non-procedural literature indicates that birth order is a critical variable that is related to parental responding to infant distress (e.g., Fielding \& Tam, 1990; Lewis \& Kreitzberg, 1979). This literature suggests that parents are more attentive and responsive to first-borns but possibly more effective and efficient with later-borns. Thus, applying this finding to the pediatric procedural pain field, it might be that parents of first-borns engage in higher quantities of comforting behavior than parents of later-borns, but that parents of laterborns are more effective in soothing their infants. Thus, the purpose of the current study was to examine whether specific parent behaviors are related to infant procedural distress, and whether this relation is mediated by birth order.

Hypothesis 1, Parent Comforting and Distracting Behavior. Similar to prior measures of parent behavior with preschooler and older child procedural distress (CAMPIS; Blount et al., 1989), it was expected that parent behavior with regard to infant distress would group into comforting and distracting behaviors. Specifically, 'comforting behaviors' would consist of verbal reassurance, kissing/hugging, rocking, and rubbing. The 'distracting behaviors' were expected to include distraction, offer toy, offer pacifier, and offer food, and tickle.

Hypothesis 2, Infant Distress and Coping Behavior. As found in research with preschool age children, (CAMPIS; Blount et al., 1989), it was anticipated that infant behavior would group into distress behaviors and coping behaviors. The 'distress behaviors' would consist of crying, screaming, negative behaviors, and flailing. The 'coping behaviors' would consist of engaging in distraction, playing alone with a toy, sucking on a pacifier, eating food, and nursing.

Hypothesis 3, Infant Distress by Infant Birth Order. Based on the notion that parents of later-born infants will have had more experience in helping infants to cope during distressing medical procedures, it was expected that first-born infants would exhibit and be rated as more distressed than later-born infants.

Hypothesis 4, Quantity of Parent Behavior by Infant Birth Order. Based on the studies of differential parent behavior with first- and later-borns (Bakeman \& Brown, 1977; Bendersky \& Lewis, 1986; Lewis \& Kreitzberg, 1979) it is expected that parents of firstborns will display overall higher quantities of behavior than parents of later-borns. 
Hypothesis 5, Relation of Parent Behavior to Infant Distress. It was hypothesized that parents' 'distracting behaviors' would be related to lower infant distress and higher infant coping and 'comforting behaviors' would be associated with higher infant distress and lower infant coping.

Hypothesis 6, Relation of Parent Behavior to Infant Distress by Birth Order.

Lastly, an interaction was expected, with parents of first-borns engaging in more comforting behaviors and fewer distraction behaviors than parents of later borns, which in turn would predict higher infant distress behaviors for the first-born infants than the laterborn infants. Conversely, it was expected that parents of later-borns would exhibit more distracting and fewer comforting behaviors, which would predict lower distress in these laterborn infants. 
Method

\section{Study Site and Participants}

Participants were 46 1-year-old infants receiving their MMR (Measles, Mumps, Rubella), HIB (Haemophilus Influenzae type b), and Varivax (Chicken Pox) immunizations. The sample of infants consisted of 30 females (22 first-born and 8 later-born) and 16 males (7 first-born and 9 later-born). The infants were ethnically representative of the study region (Northwestern United States): $76.1 \%$ were Caucasian, $8.7 \%$ were Hispanic, $6.5 \%$ did not identify ethnicity, $2.2 \%$ were African-American, $2.2 \%$ Indian, and $0.3 \%$ were Asian.

The sample was predominately middle class, and annual family income was approximately $\$ 37,543(S D=\$ 2,601)$. The typical primary caretaker was the mother $(90 \%$ mothers), who was approximately 29 years old $(S D=5.5)$, and had completed an average of 16 years of education $(S D=2.1)$. Five Caucasian nurses, ranging in age from 28 to 55, performed the immunizations.

This sample was part of a larger treatment outcome study with three, randomly assigned conditions. The first condition was distraction, where the nurse attempted to distract the child with toys and a Teletubbies ${ }^{\circledR}$ video during the immunization. In the second condition, EMLA, a topical anesthetic, was applied to the areas where the infant was to receive the immunizations. The third condition was the control condition consisting of typical treatment by the nurses. For the purposes of the current study, the participants in the distraction condition were eliminated. Removal of this group was decided because it was expected that the distraction stimuli and nurse distracting behavior would influence parent behavior. Given that parent behavior was not expected to differ related to whether or not the infants received EMLA or not, both of these condition were retained in the current investigation. No differences were found between children who did and did not receive EMLA on any of the measures of infant distress, thus, these groups of children were combined in the study. Correlations between infant treatment conditions and other variables are presented in Table 1. 
Table 1

Correlations between Infant Distress and Gender, Treatment Condition, and Family Income

\begin{tabular}{lccc}
\hline Dependent Variables & Treatment Condition & Gender & Income \\
\hline Infant Heart Rate Change & .15 & -.10 & .11 \\
Parent rating of infant distress & .17 & -.19 & -.18 \\
Nurse rating of infant distress & -.07 & $-.37 *$ & -.10 \\
Infant engaging in distraction & .19 & .00 & -.17 \\
Infant playing alone with toy & $-.29 *$ & .20 & -.09 \\
Infant sucking on pacifier & .08 & -.10 & -.06 \\
Infant consuming food & .06 & .08 & .01 \\
Infant nursing &. &. &. \\
Infant laugh &. &. &. \\
Infant negative behavior & .07 & $-.40 * *$ & -.09 \\
Infant cry & .09 & $-.32 *$ & .08 \\
Infant scream & -.14 & -.20 & -.09 \\
Infant flail & .01 & -.16 & .03 \\
Parent distraction & .10 & .01 & -.17 \\
Parent offer toy & -.17 & .18 & .10 \\
Parent offer pacifier & -.15 & -.11 & -.03 \\
Parent offer food & .09 & .24 & -.14 \\
Parent nurse &. &. &. \\
Parent maintain pacifier use & -.26 & .02 & .26 \\
Parent rub, massage, pat & -.28 & .19 & .01 \\
Parent kiss/hug & .05 & .00 & -.09 \\
Parent rock & .07 & -.01 & .09 \\
Parent verbal reassurance & -.21 & -.00 & .07 \\
\hline Note. Infant nursing, parrat
\end{tabular}

Note. Infant nursing, parent nurse infant, and infant laugh did not occur. $* p<.05 . * * p<.01$.

\section{Measures}

Demographic form. The Demographic form (Appendix A) included questions assessing parents' age, gender, relation to child, education level, occupation, spouse education and occupation, and total family income. This form also contained questions concerning the number of other children in the house, their ages, and gender and age of the target child. Finally, this form assessed the number of previous visits of the target child to this pediatric practice and the number of previous visits at other health care facilities.

Parent and Nurse Post-Shot Questionnaire. After the immunization, parents completed a visual analog scale (VAS) assessing how distressed their infant was during the injection (Appendix B). The specific question was the following: "How distressed was your baby during the shots?" The VAS consisted of a 100-mm horizontal line with end-point anchors of Not Distressed and Very Distressed. VASs are frequently used in pediatric pain studies for several reasons; they are one of the more valid and reliable forms of self-report measures, and there is less bunching of scores than with categorical pain scaling methods (McGrath, 1990; Varni, Walco, \& Wilcox, 1990). Following the immunization, the nurse 
also completed a similar VAS assessing how distressed the infant was during the injection (Appendix C). The specific question was, "How distressed was this baby during the shots?"

Physiological ratings. Infants' heart rates were obtained four times via a heart rate monitor, the Tanita Cardio ${ }^{\circledR}$. The monitor measures pulse from a fingertip and displays results digitally and has an accuracy rate of plus or minus 5\%. Heart rate was assessed at baseline when the infant and parent arrived to the pediatrician's office; pre- and postinjection, immediately prior to and following the immunization; and delayed (three to five minutes following the injection). For the purposes of this study, heart rate change, obtained by subtracting the infant's baseline heart rate from their post-injection heart rate, was the physiological measure of infant distress. Stevens and Johnston (1994) found that mean change in infant heart rate is a valid method of assessing infant pain.

\section{Observational Measures}

Measure of Adult and Infant Soothing and Distress (MAISD). The MAISD is a behavioral scale developed for this study in order to examine specific adult and infant behaviors during medical procedures (Appendix D). For this study, only infant and parent behaviors were examined. The MAISD was developed to gain a better understanding of how parent behaviors might mediate infant distress during painful medical procedures. The specific infant behaviors examined in this study included: engage in distraction, play with toy alone, suck on pacifier, consume food, nursing, laugh, negative behaviors, cry, scream, and flail. The specific parent behaviors examined in this study include: kissing, hugging, rocking, providing a pacifier, attempts to nurse, rubbing, verbal reassurance, distraction, offer toy, and offer food (see Appendix D for operational definitions of MAISD behaviors). The selection of parent behaviors and development of the MAISD was based on nurse and parent anecdotal report, observation of parent and infant behaviors during immunizations, and prior research (Blount et al., 1989; Dahlquist et al., 1994; Manne et al., 1992).

To simplify the coding procedure, the immunization procedure was coded in the following phases: Phase 1, three minutes prior to the start of cleaning immunization area until the start of the cleaning of the area; Phase 2, cleaning of the area until the nurse removes the last needle from the infant; and Phase 3, withdrawal of the last injection until two minutes have passed or the infant leaves the room, whichever comes first. In order to simplify results, reduce the number of analyses conducted, and decrease type I error rate, overall parent and infant codes collapsed across phases were used in analyses.

Two coders employed the MAISD system for the videotaped immunizations. All parent and infant behaviors were coded as present or absent on a five-second interval system. The coders learned the system from an experienced coder, and coded practice tapes until agreement scores were above $80 \%$ in agreement for three consecutive coding sessions. The interrater agreement was calculated for both the number of intervals where they observed a response (OA: number of intervals both observers agreed the response occurred divided by the total number of intervals either observer said a response occurred) and for the number of intervals where they did not observe a response (NA: number of intervals both observers agreed the response did not occur divided by the total number of intervals either observer did not code the response). Finally, total interrater agreement was also calculated (TA: total number of intervals both coders either agreed did or did not occur divided by total number of 
possible intervals). The coders coded approximately $33 \%$ (8 procedures) of the same participants to evaluate interrater agreement. Should either OA or NA have dropped below $80 \%$ for 3 consecutive sessions, the plan was for the coders to stop coding and to re-train to criterion. The coders maintained a high rate of agreement and no re-training was unnecessary. Table 2 provides the mean agreement and non-agreement reliability coefficients for the MAISD coding.

Table 2

Mean agreement for MAISD

\begin{tabular}{|c|c|c|c|}
\hline & $\begin{array}{l}\text { Occurrence } \\
\text { Agreement }\end{array}$ & $\begin{array}{c}\text { Non-occurrence } \\
\text { agreement }\end{array}$ & $\begin{array}{c}\text { Total } \\
\text { Agreement }\end{array}$ \\
\hline \multicolumn{4}{|l|}{ Infant behaviors } \\
\hline $\begin{array}{l}\text { Engage in } \\
\text { distraction }\end{array}$ & $87 \%$ & $98 \%$ & $96 \%$ \\
\hline Play alone with & $97 \%$ & $98 \%$ & $98 \%$ \\
\hline \multicolumn{4}{|l|}{ toy } \\
\hline Pacifier use & $100 \%$ & $100 \%$ & $100 \%$ \\
\hline Consume food & $*$ & $100 \%$ & $100 \%$ \\
\hline Nursing & $*$ & $100 \%$ & $100 \%$ \\
\hline Laugh & $94 \%$ & $95 \%$ & $96 \%$ \\
\hline Negative & $91 \%$ & $87 \%$ & $91 \%$ \\
\hline \multicolumn{4}{|l|}{ behavior } \\
\hline Cry & $83 \%$ & $95 \%$ & $95 \%$ \\
\hline Scream & $91 \%$ & $92 \%$ & $95 \%$ \\
\hline Flail & $87 \%$ & $97 \%$ & $97 \%$ \\
\hline \multicolumn{4}{|l|}{ Parent behaviors } \\
\hline Distraction & $81 \%$ & $89 \%$ & $89 \%$ \\
\hline Offer toy & $87 \%$ & $95 \%$ & $96 \%$ \\
\hline Offer pacifier & $89 \%$ & $96 \%$ & $97 \%$ \\
\hline Maintain pacifier & $100 \%$ & $100 \%$ & $100 \%$ \\
\hline \multicolumn{4}{|l|}{ use } \\
\hline Offer food & $*$ & $100 \%$ & $100 \%$ \\
\hline Attempts to & $*$ & $100 \%$ & $100 \%$ \\
\hline \multicolumn{4}{|l|}{ Nurse } \\
\hline Rub, Massage, & $91 \%$ & $98 \%$ & $95 \%$ \\
\hline \multicolumn{4}{|l|}{ Pat } \\
\hline Hug/Kiss & $81 \%$ & $98 \%$ & $97 \%$ \\
\hline Rock & $81 \%$ & $95 \%$ & $94 \%$ \\
\hline $\begin{array}{l}\text { Verbal } \\
\text { reassurance }\end{array}$ & $81 \%$ & $92 \%$ & $93 \%$ \\
\hline
\end{tabular}

* Behavior did not occur on the reliability tapes.

Descriptive analyses revealed that many of the parent behaviors were occurring at a low frequency. For example, offer toy $(.009 \%)$, offer pacifier $(.006 \%)$, offer food $(.002 \%)$, and attempt to nurse the infant $(.000 \%)$ all occurred during less than $1 \%$ of the 5 -second intervals. The remaining behaviors all occurred in at least $5 \%$ of the 5 -second intervals: Kiss/Hug (5\%), Rub (7\%), Rock (8\%), Parent Distraction (12\%), and Verbal Reassurance 
(21\%). Due to the extremely low frequency of parents attempting to nurse their infants, offering toys, pacifier, or food to their infants, and to minimize the number of statistical tests conducted, these parent behaviors were eliminated from the study.

As with parent behaviors, descriptive analyses were conducted and revealed that many infant behaviors also were occurring at an extremely low frequency; consume food $(.001 \%)$, attempt to nurse $(.000 \%)$, and laugh $(.000 \%)$ all occurred less than $1 \%$ during the 5second intervals. Other behaviors, including play alone with toy (3\%), scream (3\%), and flail (1\%) also occurred infrequently. In order to avoid analyses on extremely infrequent behaviors (and increase the risk of type 1 error), it was decided to only include infant behaviors that occurred in more than $5 \%$ of the total number of 5 -second intervals in the analyses. The remaining behaviors and their corresponding rate of occurrence are the following: Engages in distraction (8\%), Suck on pacifier (8\%), Cry (36\%), and Negative Behaviors (52\%).

To determine agreement for the MAISD, the researcher also employed a Cohen's kappa for 8 randomly selected participants (approximately 33\% of the sample). The Cohen's kappa is a conservative statistic that can be employed to correct for chance agreement (Bakeman \& Gottman, 1987; Cohen, 1960). Kappa coefficients for the parent behavior category were as follows: Kiss/Hug (.60), Rub (.64), Rock (.59), Distraction (.66), and Verbal reassurance (.69). Kappa coefficients for the infant behavior category were as follows: Engages in distraction (.66), Suck on Pacifier (.87), Cry (.92), Negative behavior (.88). These scores represent fair to excellent levels of agreement (Fleiss, 1981).

\section{Procedure}

The pediatricians' receptionist queried eligible parents while scheduling their infant's appointment on the telephone. Specifically, the receptionist asked whether they were interested in participating in a study focusing on ways to reduce their infant's distress during immunizations. Interested parents were contacted by telephone by the primary investigator or a research assistant and provided with more information about the study.

On the day of the immunization, a research assistant met parents and infants at the pediatrician's office. Parents were informed about the purpose and procedures of the study and provided a consent form to complete. The research assistant obtained a baseline measure of the infant's pulse and helped the parent complete the Demographic form prior to the family being called back to the treatment room. When the family was taken to the treatment room, the infant underwent a physical checkup prior to the nurse administering the immunizations. Just before the nurse gave the immunizations, a research assistant turned on a video camera to record the procedure and left the room. Immediately ( 0 to 1 minutes $)$ prior to and following the immunization, the nurse obtained the infant's pulse and then completed the post-procedure questionnaire. Following the procedure, the research assistant met the family in the waiting room to help the parent complete the post-procedure questionnaires and to obtain the delayed infant heart rate. 
Results

\section{Preliminary Analyses}

Given the fact that procedural distress is a relatively novel area of research, it was decided to set the alpha level at a liberal .05. It is important to bear in mind that there is increased potential for Type 1 error as the number of analyses increases. Preliminary analyses were performed to evaluate whether any extraneous or nuisance variables should be taken into account for further analyses. Infant gender (via Point Biserial) and family income (via Pearson product-moment) were correlated with infant distress (i.e., parent-report, nursereport, heart rate change, MAISD Infant behaviors) and parent behavior (i.e., MAISD Parent Behaviors). Correlations were considered significant at the .05 alpha level (two-tailed). Infant gender was related significantly to nurse rating of child distress $r_{p b}(43)=-.37, p<.01$, with females $(M=64.16, S D=23.30)$ being rated as significantly more distressed than males $(M$ $=45.40, S D=21.37), t(43)=2.5, p<.05$. Additionally, infant gender was significantly correlated with MAISD infant total rate of nonverbal negative behavior, $r_{p b}(46)=-.32$, $p<.05$, and total rate of crying, $r_{p b}(46)=-.41, p<.05$. Female infants $(M=.97, S D=.37)$ exhibited significantly higher rates of nonverbal negative behavior than males $(M=.68, S D=$ $.25), t(46)=2.7, p<.05$. Females $(M=.40, S D=.20)$ also exhibited significantly higher rates of crying than did males $(M=.27, S D=.13), t(46)=2.3, p<.05$. Given these significant gender differences, subsequent analyses with infant cry, infant nonverbal negative behavior, and nurse post-shot rating of infant distress was examined separately by gender.

\section{Analyses for Hypothesis 1, Parent Behavior}

The means and standard deviations of all study variables for first-born and later-born infants are presented in Table 3. To determine whether MAISD parent behaviors (kiss/hug, rock, rub, verbal reassurance) would comprise a "comforting" or a "distracting" category, the behaviors were evaluated using Cronbach's alpha inter-item correlation. Items with an alpha level of .7 were considered to comprise the grouping. Results indicated that none of these behaviors reliably intercorrelated, as such, all parent behaviors were examined separately. 
Table 3

Means and Standard Deviations for Infant Distress Variables by Birth Order

\begin{tabular}{lcccc}
\multicolumn{1}{c}{ Variables } & Later-Born & & \\
\hline & & $S D$ & $M$ & $S D$ \\
Infant Heart Rate Change & 21.41 & 31.25 & 15.75 & 43.58 \\
Nurse Ratings of Female Infant Distress & 68.95 & 23.14 & 20.30 & 7.17 \\
Nurse Ratings of Male Infant Distress & 46.50 & 23.51 & 44.66 & 21.26 \\
Parent Ratings of Infant Distress & 86.03 & 17.90 & 77.47 & 26.98 \\
Parent Behavior & & & & \\
$\quad$ Rub, Massage, Pat & .04 & .07 & .09 & .09 \\
Distraction & .13 & .12 & .09 & .09 \\
Kiss/Hug & .05 & .06 & .04 & .03 \\
Rock & .09 & .09 & .06 & .07 \\
Verbal Reassurance & .21 & .10 & .19 & .11 \\
Infant Behaviors & & & & \\
$\quad$ Engage in Distraction & .09 & .11 & .06 & .07 \\
Suck on Pacifier & .06 & .18 & .11 & .19 \\
Negative Behavior (female) & .56 & .19 & .58 & .16 \\
Negative Behavior (male) & .41 & .12 & .42 & .14 \\
Cry (female) & .38 & .19 & .46 & .24 \\
Cry (male) & .22 & .10 & .30 & .14 \\
Infant Distress Behavior (female) & .94 & .36 & 1.05 & .40 \\
Infant Distress Behavior (male) & .63 & .22 & .72 & .28 \\
\hline
\end{tabular}

Analyses for Hypothesis 2, Infant Behavior

To determine whether MAISD infant behaviors (negative behavior, cry, engage in distraction, and suck on pacifier) would comprise a "comforting" or a "distracting" categories the behaviors were evaluated using Cronbach's alpha inter-item correlation. Results indicated that cry and infant negative behavior were significantly correlated, $r(46)=$ $.80, p<.01$, thus they were combined by summation for all further analyses; this grouping will be referred to as Infant Distress. Engage in distraction and suck on pacifier were not correlated and will be examined separately in further analyses.

\section{Analyses for Hypothesis 3, Infant Distress by Birth Order}

To determine whether first-born infants were more distressed than later-born infants, independent sample $t$ tests were conducted with birth order as the grouping variable and all dependent variables of infant distress (Heart Rate Change, Nurse and Parent Ratings of Infant Distress, and Infant Distress Behavior) as the testing variables. Results indicated that infant distress behavior did not differ significantly between first-born and later-born infants. These results are presented in Table 3.

\section{Analyses for Hypothesis 4, Quantity of Parent Behavior by Infant Birth Order}

To determine whether parents of first-born infants engage in a greater number of behaviors with their infants than parents of later-born infants, independent sample $t$ tests were conducted with birth order as the grouping variable and quantity of parent behavior as the testing variable. Results indicated that the quantity of behavior did not differ significantly 
between parents of later-borns $(M=.60, S D=.24)$ and first-borns $(M=.48, S D=.25), t(46)$ $=1.5, p=.12$.

\section{Analyses for Hypothesis 5, Relation of Parent Behavior to Infant Distress}

To determine whether parents' distraction, rubbing, hugging/kissing, rocking, or verbal reassurance were related to infants' engaging in distraction, sucking on pacifiers, distress behavior, parent and nurse ratings of infant distress, or infant heart rate change, pearson product moment correlational analyses were conducted. Given the ample literature evidencing positive relations between parent reassurance and child distress and also parent distraction and child engage in distraction (e.g., Blount et al., 1989; Blount et al., 1991; Frank et al., 1995), and that the directions of these associations were predicted, these analyses were conducted with one-tailed tests. The analyses with parent rub, kiss/hug, and rock used twotailed tests because these were exploratory statistics. Analyses revealed that infant rate of sucking on a pacifier was significantly positively correlated with the parent behavior of $\mathrm{kiss} / \mathrm{hug}, r(46)=.32, p<.05$. Additionally, the rate of parents' attempts to engage their infants in distraction positively correlated with the rate of infants engaging in distraction, $r(46)=$ $.57, p<.01$. Finally, the rate of parents' verbal reassurance was significantly correlated with both male infants' distress behaviors $r(16)=.49, p<.05$, as well as with female infants' distress behavior $r(30)=.31, p<.05$. These results are presented in Table 4 .

Table 4

Correlations of Parent Behaviors and Infant Distress

\begin{tabular}{|c|c|c|c|c|c|}
\hline \multirow[b]{2}{*}{ Infant Measures } & \multirow[b]{2}{*}{ Distraction } & \multicolumn{3}{|c|}{ Parent Behaviors } & \multirow[b]{2}{*}{$\begin{array}{c}\text { Verbal } \\
\text { Reassurance }\end{array}$} \\
\hline & & Rub & Kiss/Hug & Rock & \\
\hline Distraction & $.57^{b b}$ & -.12 & .12 & .02 & -.07 \\
\hline Suck on Pacifier & -.01 & -.18 & $.32 *$ & -.02 & -.08 \\
\hline $\begin{array}{l}\text { Distress Behaviors } \\
\text { (male infant) }\end{array}$ & .03 & .36 & -.32 & -.08 & $.49^{b}$ \\
\hline $\begin{array}{l}\text { Distress Behaviors } \\
\text { (female infant) }\end{array}$ & -.19 & -.20 & -.16 & -.17 & $.32^{b}$ \\
\hline $\begin{array}{l}\text { Nurse rating of } \\
\text { Distress (male } \\
\text { infant) }\end{array}$ & .26 & -.27 & -.28 & -.28 & .04 \\
\hline $\begin{array}{l}\text { Nurse rating of } \\
\text { Distress (female } \\
\text { infant) }\end{array}$ & .20 & -.37 & -.14 & -.18 & .128 \\
\hline $\begin{array}{l}\text { Parent rating of } \\
\text { Distress }\end{array}$ & .15 & -.16 & -.20 & -.08 & .16 \\
\hline Infant Heart Rate & -.04 & -.15 & -.08 & -.12 & -.01 \\
\hline
\end{tabular}

Analyses for Hypothesis 6, Relation of Parent Behavior to Infant Distress by Birth Order

To determine the predictive power of specific parent behaviors by birth order interactions on infant behavior and distress stepwise linear regressions were employed. Interaction variables were computed by multiplying each parent behavior by birth order 
(dummy coding was used with 1 for first-born and 2 for later-born). This technique is commonly suggested as a way to examine interactions in regression analyses (Cohen \& Cohen, 1983). None of the parent behavior by birth order interaction variables significantly predicted infant distress or behavior. However, one trend emerged. Specifically, parent behavior by birth order accounted for $52 \%$ of the variance in infant distress behavior, $F(6$, $13)=2.38, p<.09$ with parent verbal reassurance by birth order interaction significantly predicting infant distress behavior $t(19)=3.25, p<.01$. Higher rates of verbal reassurance were linked to increases in distress behavior for first-born infants only, $r(29)=.39, p<.05$. These results are presented in Table 5. Response means, interaction means, and standard deviations are presented in Table 3.

Table 5

Summary of Stepwise Regression Analysis for Variables Predicting Infant Distress Behavior

$$
\begin{array}{lllll}
\text { Variable } & d f & R^{2} & B
\end{array}
$$

Step 1

Infant gender

1,18

.07

$-.26$

$-1.1$

Step 2

Parent Rock by birth order

5,13

.52

$-.06$

Parent Kiss/Hug by birth order

$-.22$

Parent Rub by birth order

$-.65$

.92

Parent Verbal Reassurance by birth order $3.25^{* *}$

Parent Distraction by birth order

.01

.07 


\section{Discussion}

The purpose of this study was to examine parent-infant interactions during immunizations. Additionally, the study was conducted to determine whether any parent behaviors were related to higher levels of infant distress, and whether parent behavior and infant distress differed as a function of infant birth-order. In general, the results did not provide strong support for the proposed hypotheses; however, given the novelty of research examining correlates of infant procedural distress, this is not entirely surprising. In the preliminary analyses, some interesting findings emerged. Specifically, nurses rated female infants as more distressed than male infants, and female infants displayed more overt distress behavior than male infants. One explanation for this gender difference is that male and female infants express distress differently. In fact, Guinsburg and colleagues (2000) found that female infants were rated as demonstrating more facial expressions of pain than males during heelstick procedures. In addition, studies of adult pain have consistently demonstrated that females express more pain than males (e.g., LaResche, 1999). Of note, the majority of studies with preschoolers and older children undergoing painful procedures have not revealed gender differences (e.g., Cohen et al., 1997, Cohen et al., 1999). It is curious, however, that parents in the current study did not rate female infants as significantly more distressed than male infants. It is possible that parents' ratings were based on comparisons with how their own infant typically behaves, and the nurses and the coders were comparing infant behavior to the norm behavior of other infants. This explanation is consistent with findings in children's distress literature, which has demonstrated that there are often discrepancies between parent and nurse reports of children's distress (Schneider \& LoBiando, 1992), and that nurse report and parent report of pain may be based upon differing information (Manne, Jacobsen, \& Redd, 1992).

Counter to hypotheses, parents' behaviors with infants did not cluster along the same lines found with parents' behaviors with preschoolers (Blount et al., 1989). This lends some support to the argument that parents employ different coaching behaviors depending on the age of their child. Related to this, one must question the appropriateness of employing observational measures of parent behavior with preschoolers to populations of infants, such as was done by Sweet, McGrath, and Symons (1999). For example, the parent behavior of commands for the child to cope, which is included in the CAMPIS-R (Blount et al., 1997), would likely not be displayed by a parent interacting with his/her infant. Although parents engage in different behaviors with their infants than with their preschoolers, the current study is similar to the work with preschoolers in that parents engage in overall low rates of behavior during an immunization procedure (Cohen, Manimala, \& Blount, 2000). These results are important in that they indicate that parents might be unsure of how to best behave to assist their child during a distressing medical event, and parents might opt to allow the medical staff to take a more dominant role in comforting the distressed child.

There were no differences in parent behavior by the birth order of their child. This result is interesting given the findings that parents of first-borns typically are more responsive and interactive with their children (e.g., Belsky et al., 1984; Donate-Bartfield \& Passman, 1985). A power-analysis revealed that there was sufficient power (.89) to detect these findings in the current sample if they did in fact exist. The primary difference between 
the current and prior studies of parent behavior with their children is that previous examinations were conducted in naturalistic home environments. Perhaps the novel medical setting, brief period of interaction, and high distress of the infants influenced parents' typical behavior.

In terms of the infant distress behaviors, two behaviors, cry and nonverbal negative behavior (i.e., furrowed brow, eyes closed tightly, and open lips) were strongly positively related. Of note, other infant behaviors occurred at a very low rate. However it is important to consider that many of these behaviors (such as infant consume food) were dependent upon the parent providing an opportunity for the infant to engage in the behavior. Despite the low frequencies of some of the infant behaviors, many of the infant behaviors exhibited at higher frequencies would not have been assessed with other measures of infant procedural distress. For example, the popular and widely used Neonatal Facial Coding System (NFCS, Grunau \& Craig, 1987) assesses only infant facial expressions of distress and does not capture other distress behaviors (e.g., cry) or non-distress behaviors (e.g., engage in distraction), which might provide valuable information and help guide clinical intervention. In addition, from a practical point of view, given the changing position of the child and adults in the treatment room, examining discrete facial movements (e.g., cupped tongue) it not always possible. Thus, a more comprehensive scale, such as the MAISD, is warranted, especially when studying a new topic on inquiry.

Three parent behaviors were found to relate to infant behaviors and infant distress. First, the parent behavior of verbal reassurance was significantly related to infant distress behavior, both for male and female infants. This finding is consistent with prior studies demonstrating that verbal reassurance predicts infant distress (e.g., Blount et al., 1989; Sweet $\&$ McGrath, 1998). Because the parent-infant interactions were not experimentally manipulated or examined sequentially, it is not possible to make causal statements; however one might expect that if parents react to infants' distress with reassuring comments, in a reciprocal fashion, these comments could serve to reinforce infants' distress behaviors. Infants who receive immunizations initially might not know how to react to the pain and parental reassurance could serve as a prompt for distress behaviors. In fact, an experimental study with preschoolers has demonstrated that parental reassurance does prompt child distress (Manimala, Blount, \& Cohen, 2000). Further research is needed to examine the specific causal relations between parents' verbal reassurance and infants' distress.

It is heartening that parents' distraction behavior was significantly related to infants' engaging in distraction. However, parent distraction was not negatively related to infant distress, as has been demonstrated in the preschooler literature (e.g., Blount et al., 1989). Perhaps these untrained parents' use of distraction, and the fact that the parents were not provided with distraction stimuli, helps explain this lack of relation. Supporting this interpretation, a recent experimental investigation demonstrated that trained nurses are able to reduce infant distress with adequate training and provision of distraction stimuli (Cohen, in press).

In the current study, the parent behavior by birth order interaction did not prove to be a strong predictor of infant behavior or distress. This is consistent with the fact that first-born and later-born infants did not differ significantly on measures of infant distress and behavior. 
However, the parent behavior by birth order interaction variable did relate to parents' verbal reassurance, with parents of first-borns engaging in more reassurance. Higher rates of verbal reassurance predicted infants' distress for first-born infants only. Given that previous research has consistently found that parents' verbal reassurance is related to infant and child distress (Blount et al., 1989; Blount et al., 1991; Sweet \& McGrath, 1998), it is curious that this was only the case for first-born infants in the current study. Although no differences were found in overall behavior between the groups of parents, it might be that parents of first-borns engage in more or a different sort of reassurance than parents of later-borns. On the other hand, it might be that parents of first-borns respond more frequently with reassurance to their distressed infants than parents of later-borns. Future work is needed to clarify this relation.

There are several explanations for why the majority of anticipated birth order differences were not found. Whereas birth order may influence general parent-infant interactions, these differences in behavior were not observable during the brief immunization period. Had parent-infant interactions been examined over a longer period of time, birth order differences may have become clearer. Potential birth-order differences may have been obscured by the fact that this immunization was not truly the infant's first painful experience. As such even the parents of first-born infants have had many opportunities to learn how to sooth their distressed infants. Detecting birth order differences in parent behavior was further complicated by the fact that parents were engaging in very few behaviors with their infants. In addition, stimuli in the medical environment might influence parents' normal responding patterns, and they might defer soothing to the medical staff. In addition, given literature documenting parents' high anxiety during their children's procedures (e.g., Cohen et al., 1997; Jay et al., 1985), these parents own distress might have interfered with their regular patterns of interacting with, and soothing their infants.

Limitations of this study should be noted. For example, parent-infant interactions were not examined sequentially or manipulated experimentally. Thus, as a nonexperimental study, it is not possible to fully understand the causal role of parent behaviors on infant immunization distress. Another limitation is the small sample size. With a larger sample and more power, other findings might have emerged. It also might have been problematic to classify birth order with only two levels, first versus later-born. In specific, many of the laterborn infants in this study were the third or even fourth child in a family. By lumping together all of the later-born infants into one category, the true influence of parenting experience, which might exponentially increase with the number of offspring, might not have emerged. Other factors such as infant temperament might have enlightened some of the results. For instance, temperament might influence infants' distress reaction and expression and also the strategies that parents choose to employ with their infants. Lastly, whereas the homogeneity of the sample increased internal validity, external validity was compromised in terms of applying these findings to children from other backgrounds, of different ages, and undergoing different procedures. A larger more diverse sample might increase the frequency of some of the behaviors found to occur at low rates in the current study.

Future research in the area of infant distress should examine parent-infant interactions sequentially and experimentally. These types of studies could lead to direct recommendations for parents about what they should and should not do to assist their infant during painful 
events. However, it is important to first conduct the necessary base of explicative studies to guide the development of interventions (Blount et al., 2000). Given the current findings, future research should also consider infant gender when employing nurse or observational report of infant distress. Although the current study found little related to birth order, given the novelty of this question, future studies with larger populations and more precise measures should continue to explore this potentially valuable variable.

In summary, the current study revealed that females were more distressed than males, both by nurses' reports and on a measure of overt distress behavior. Additionally, the patterns and influence of parents' behavior during infants' distressing procedures were found to be dissimilar to those of parents' behavior during preschoolers' distressing procedures; however some behaviors, such as verbal reassurance, appear to have a similar influence on both preschoolers' and infants' procedural behaviors. Finally, birth order did not prove to be a consistently distinguishing factor in parent behavior, infant procedural distress, or interactions between these two variables. Considering both the findings in the current study, clinicians and researchers should appreciate that the large body of information garnered from studies with preschoolers and older children undergoing medical procedures might not be applicable to the unique age of infancy. In addition, given the dearth of research and clinical attention to this important topic, it is essential that health care professionals devote more time and energy to the evaluation and treatment of infant procedural distress. 


\section{References}

Ainsworth, M.D.S., Blehar, M.C., Waters, E., \& Wall, S. (1978). Patterns of attachment: A psychological study of the strange situation. Potomac, Md: Lawrence Erlbaum.

Anand, K.J.S. \& Hickey, P.R. (1987). Pain and its effects in the human neonate and fetus. New England Journal of Medicine, 317, 1321-1329.

Anand, K.J.S., \& McGrath. P.J. (1993a). An overview of current issues and their historical background. In K.J.S. Anand and P.J. McGrath's (Eds.), Pain in Neonates (pp.1-18). Amsterdam: Elsevier.

Attia, J., Amiel-Tison, C., Mayer, M.N. (1987). Measurement of postoperative pain and narcotic administration in infants using a new clinical score system. Anesthesiology, 67, A532.

Bakeman, R., \& Brown, J.V. (1977). Behavioral dialogues: An approach to the assessment of mother-infant interaction. Child Development, 48, 195-203.

Bakeman, R., \& Gottman, J.M. (1987). Observing interaction: An introduction to sequential analysis (2nd ed.). New York: Cambridge.

Bell, S.M., \& Ainsworth, M.D.S. (1972). Infant crying and maternal responsiveness. Child Development, 43, 1171-1190.

Belsky, J., Gilstrap, B., \& Rovine, M. (1984). The Pennsylvania infant and family development project, I. Stability and change in mother-infant and father-infant interaction in a family setting at one, three and nine months. Child Development, 55, 692-705.

Bendersky, M., \& Lewis, M. (1986). The impact of birth order on mother infant interactions in preterm and sick infants. Journal of Developmental \& Behavioral Pediatrics, 7, 242246.

Blount, R.L., Bunke, V.L., \& Zaff, J.F. (2000). The integration of basic research, treatment research, and clinical practice in pediatric psychology. In D. Drotar (Ed.), Handbook of research in pediatric and clinical child psychology (pp. 491-510). New York: Kluwer Academic/Plenum Publishers.

Blount, R.L., Corbin, S.M., Sturges, J.W., Wolfe, V.V., Prater, J.M., \& James, L.D. (1989). The relationship between adults' behavior and child coping and distress during BMA/LP procedures: A sequential analysis. Behavior Therapy, 20, 585-601.

Blount, R.L., Landolf-Fritsche, B., Powers, S.W., \& Sturges, J.W. (1991). Differences between high and low coping children and between parent and staff behaviors during painful medical procedures. Journal of Pediatric Psychology, 16, 795-809. 
Blount, R.L., Powers, S.W., Cotter, M.W., Swan, S., \& Free, K. (1994). Making the system work: Training pediatric oncology patients to cope with their parents to coach them during BMA/LP procedures. Behavior Modification, 18, 6-31.

Broome, M.E. \& Endsley, R. (1989). Parent and child behavior during immunization. Pain, $37,85-92$.

Burokas, L. (1985) Factor's affecting nurses' decisions to medicate pediatric patients after surgery. Heart Lung, 14, 373-379.

Clancy, G.T., Anand, K.J.S., \& Lally, P. (1992). Neonatal pain management. Critical Care Nurse Clinical North America, 4, 527-535.

Cohen, J.A. (1960). A coefficient of agreement for nominal scales. Educational and Psychological Measurement, 20, 37-46.

Cohen, J., \& Cohen, P. (1983). Applied multiple regression/correlation analysis for the behavioral sciences $\left(2^{\text {nd }}\right.$ ed.). Hillsdale N.J.: Lawrence Erlbaum.

Cohen, L.L. (in press). Reducing infant immunization distress through distraction. Health Psychology.

Cohen, L.L., Blount, R.L., Cohen, R.J., Schaen, E.R., \& Zaff, J.F. (1999). Comparative study of distraction versus topical anesthesia for pediatric pain management during immunization. Health Psychology, 18, 1-8.

Cohen, L.L., Blount, R.L., \& Panopoulos, G. (1997). Nurse coaching and cartoon distraction: An effective and practical intervention to reduce child, parent, and nurse distress during immunization. Journal of Pediatric Psychology, 22, 355-370.

Cohen, L.L., Manimala, R., \& Blount, R.L. (2000). Easier said than done: What parents say they do and what they do during children's immunization. Children's Health Care, 29, 79-86.

Cohen, S.E., \& Beckwith, L. (1977). Caregiving behaviors and early cognitive development as related to ordinal position in preterm infants. Child Development, 48, 152-157.

Craig, K.D., Whitfield, M.F., Grunau, R.V.E., Linton, J., \& Hakjistavropoulos, H.D. (1993). Pain in the preterm neonate: behavioral and physiological indices. Pain, 52, 287-299.

Dahlquist, L.M., Power, T.G., Cox, C.N. \& Fernbach, D.J. (1994). Parenting and child distress during cancer procedures: A multidimensional assessment. Children's Health Care, 23, 149-166. 
Donate-Bartfield, E., \& Passman, R.H. (1985). Attentiveness of mothers and fathers to their baby's cries. Infant Behavior \& Development, 8, 385-393.

Fielding, R., \& Tam, F.S.H. (1990). Maternal responses to expressed distress of Chinese children hospitalized for elective surgery. Psychologia, 33, 100-105.

Finley, G.A., \& McGrath, P.J. (Eds.). (1998). Measurement of pain in infants and children. Seattle: IASP Press.

Finley, G.A., McGrath, P.J., Forward, S.P., McNeill, G., \& Fitzgerald, P. (1996). Parent's management of children's pain following 'minor' surgery. Pain, 64, 83-87.

Fitzgerald, M. (1991). Development of pain mechanisms. Behavioral Medicine Bulletin, 47, 667-675.

Fitzgerald, M. \& Anand, K.J.S. Developmental neuroanatomy and neurophysiology of pain. In : Schechter NL. Berde, C.B, Yaster M, eds. Pain in Infants, Children and Adolescents. Baltimore, MD: Willimans \& Wilkins; 1993:11-31.

Fitzgerald, M. \& Andrews, K. (1997). Biological barriers to pain management in infants and children. Clinical Journal of Pain, 13, 138-143.

Fitzgerald, M., Millard, C. \& McIntosh, N. (1989). Cutaneous hypersensitivity following peripheral tissue damage in newborn infants and its reversal with topical anaesthesia. Pain, 39, 31-36.

Fleiss, J. L. (1981). Statistical methods for rates and proportions. New York: Wiley.

Frank, N.C., Blount, R.L., Smith, A.J., Manimala, M.R. \& Martin, J.K. (1994). Parent and staff behavior, previous child medical experience, and maternal anxiety as they relate to child procedural distress and coping. Journal of Pediatric Psychology, 20, 277-289.

Grunau, R.V.E. \& Craig, K.D. (1987). Pain expressions in neonates: facial action and cry. Pain, 28, 395-410.

Guinsburg, R., de Araujo Peres, C., Branco de Almedia, M.F., Balda, R. C. X., Berenguel, R.C., Tonelotto, J., Kopelman, B.I. (2000). Differences in pain expression between mail and female newborn infants. Pain, 85, 127-133.

Gunnar, M.R., Porter, F.L., Wolf, C.M., Rigatuso, J. \& Larson, M.C. (1995). Neonatal stress reactivity: Predictions to later emotional temperment. Child Development. 66, 1-13.

Hatch, D.J. (1987). Analgesia in the neonate. Behavioral Medicine Journal, 294, 920.

Huebner, R.R., \& Izard, C.E. (1988). Mothers' responses to infants' facial expressions of sadness, anger, and physical distress. Motivation and Emotion, 12, 185-196. 
Jacobsen, P.B., Manne, S.L., Gorfinkle, K., \& Schorr, O. (1990). Analysis of child and parent behavior during painful medical procedures. Health Psychology, 9, 559-576.

Jay, S.M., Elliott, C.H., Ozolins, M., Olson, R.A., \& Pruitt, S.D. (1985). Behavioral management of children's distress during painful medical procedures. Behavioral Research and Therapy, 23, 513-520.

Johnston, C.C., Stevens, B.J., Yang, F. \& Horton, L. (1995). Differential response to pain by very premature neonates. Pain, 61, 471-479.

Johnston, C.C., Stremler, R.L., Stevens, B.J. \& Horton, L.J. (1997). Effectiveness of oral sucrose and simulated rocking on pain response in preterm neonates. Pain, 72, 193-199.

Kagan, J. (1994). On the nature of emotion. Monographs of the Society for Research in Child Development, 59, 2-3.

Lawrence, J., Alcock, D., McGrath, P., Kay, J., MacMurrary, S.B., \& Dulberg, C. (1993). The development of a tool to assess neonatal pain. Neonatal Network, 12, 59-66.

Lewis, M., \& Kreitzberg, V. (1979). Effects of birth order and spacing on mother-infant interactions. Developmental Psychology, 16, 617-625.

Lewis, M. \& Ramsay, D.S. (1999). Effect of maternal soothing on infant stress responsivity. Child Development, 70, 11-20.

Manimala, M., Blount, R.L. \& Cohen, L.L. (2000). The Influence of parental reassurance and distraction on children's reactions to an aversive medical procedure. Children's Health Care, 29, 161-177.

Manne, S.L., Bakeman, R., Jacobsen, P.B., Gorfinkle, K., Bernstein, D., \& Redd, W.H. (1992). Adult-child interaction during invasive medical procedures. Health Psychology, $11,241-249$.

Manne, S.L., Jacobsen, P.B., \& Redd, W.H. (1992). Assessment of acute pediatric pain: do child self-report, parent ratings and nurse ratings measure the same phenomenon. Pain, $48,45-52$.

Manne, S.L., Redd, W.H., Jacobsen, P.B., Gorfinkle, K., Schorr, O., \& Rapkin, B. (1990). Behavioral intervention to reduce child and parent distress during venipuncture. Journal of Consulting and Clinical Psychology, 58, 565-572.

Mathews, J.R., McGrath, P.J., \& Pigeon, H. Assessment and measurement of pain in children. In N.L. Schechter, C.B. Berde, M. Yaster (Eds.). Pain in Infants, Children and Adolescents (pp. 97-112). Baltimore, MD: Willimans \& Wilkins 
McGrath, P.J., Johnson, G., Goodman, J.T., Schillinger, J., Dunn, J., \& Chapman, J.A., (1985) CHEOPS: A behavioral scale for rating postoperative pain in children. In H.L. Field, R. Dubner, \& F. Cervero (Eds.), Advances in pain research and therapy: Vol. 9. Proceedings of the fourth world congress on pain (pp. 395-402). New York: Raven Press.

McLaughlin, C.R., Hull, J.G., Edwards, W.H., Cramer, C.P., \& Dewey, W.L. (1993). Neonatal pain: A comprehensive survey of attitudes and practices. Journal of Pain and Symptom Management, 8, 7-16.

Owens, M.E., \& Todt, E.H. (1984). Pain in infancy: neonatal reaction to a heal lance. Pain, 20, 77-86.

Porter, F.L., Grunau, R.E., \& Anand, K.J.S. (1999). Long-terms effects of pain in infants. Developmental and Behavioral Pediatrics, 20, 253-261.

Porter, F.L., Wolf, C.M., Gold, J.G., Lotsoff, D., \& Miller, J.P. (1997). Pain and pain management in newborn infants: A survey of physicians and nurses. Pediatrics, 100, 626-632.

Powers, S.W. (1999). Empirically supported treatments in pediatric psychology: Procedurerelated pain. Journal of Pediatric Psychology, 24, 131-145.

Schechter, N.L., Berde, C.B., \& Yaster, M. Pain in infants, children and adolescents; an overview. In :Schechter NL. Berde, C.B, Yaster M, eds. Pain in Infants, Children and Adolescents. Baltimore, MD: Willimans \& Wilkins; 1993:3-10.

Schneider, E.M. \& LoBiondo-Wood, G. (1992). Perceptions of procedural pain: Parents, nurse, and children. Children's Health Care, 21, 157-162.

Stevens, B.J. \& Johnston, C. (1994). Physiological responses of premature infants to a painful stimulus. Nursing Research, 43, 226-231.

Swafford, L.I. \& Allen, D. (1968). Pain relief in the pediatric patient. Medical Clinics of North America 52, 131-136.

Sweet, S.D., \& McGrath, P.J. (1998). Relative importance of mothers' versus medical staffs' behavior in the prediction of infant immunization pain behavior. Journal of Pediatric Psychology, 23, 249-256.

Sweet, S.D., McGrath, P.J. \& Symons, D. (1999). The roles of child reactivity and parenting context in infant pain response. Pain, 80, 655- 661.

Taddio, A., Katz, J., Ilersich, A.L., \& Koren, G. (1997). Effect of neonatal circumcision on pain response during subsequent routine vaccination. The Lancet, 349, 599-603. 
Taddio, A., Nullman, I., Goldbach, M., Ipp, M., \& Koren, G. (1994). Use of lidocaineprilocaine cream for vaccination pain in infants. Journal of Pediatrics, 124, 643-648.

Thoman, E.B., Turner, A.M., Leiderman, A.H., \& Barnett, C.R. (1970). Neonate-mother interactions: Effects of parity on feeding behavior. Child Development, 41, 1103-1111.

Varni, J.W., Walco, G.A., \& Wilcox, K.T. (1990). Cognitive-biobehavioral assessment and treatment of pediatric pain. In A. M. Gross \& R. S. Drabman (Eds.), Handbook of clinical behavioral pediatrics (pp. 83-97). New York: Plenum.

Walco, G.A., Cassidy, R.C., \& Schechter, N.L. (1994). Pain, hurt and harm: The ethics of pain control in infants and children. New England Journal of Medicine, 331, 541-544.

Watson, J.S. (1966). The development and generalization of "contingency awareness" in early infancy: Some hypotheses. Merrill-Palmer Quarterly, 12, 123-135.

Watson, J.S. (1985). Contingency perception in early social development. In T.M. Field \& N.A. Fox (Eds.), Social perception in infants (pp.157-176). Norwood, NJ: Ablex.

Zimmerman, R.R., \& Torrey, C. C. Ontogeny of learning, in Schrier AM, Harlow HF, Stollnitz F (eds): Behavior of Nonhuman Primates: Modern Research Trends, vol 2. New York, NY, Academic Press, 1965, pp 405. 
Demographic Form

\section{Appendix A}

Date___ Code \#___ Condition_

What is your relation to the infant? Your gender? Your race? Your date of birth? Your education (highest grade completed/degree)? Spouse's education (highest grade completed/degree)?

Your occupation? Spouse's occupation?

Total family income? \$ per year

What is the gender of this infant? Infant's race? Infant's date of birth? How many other children live in the home? What are their ages?

Approximately how many times has this infant been to this pediatricians' office? Other pediatricians' offices?

If other than regular check-ups and immunizations, please describe.

Has this infant had any injections since the last ( 9 month) immunization? How many and why? 


\section{Appendix B \\ Parent Post-Shot Questionnaire}

Code \#___ Condition___ Date

How distressed was your baby during the shot?

Not Distressed

Very

Distressed 
Parent-Infant Interactions 31

\section{Appendix C \\ Nurse Post-Shot Questionnaire}

Code \# Date

How distressed was this baby during the shots?

Not Distressed

Very Distressed 


\section{Appendix D \\ Measure of Adult and Infant Soothing and Distress (MAISD) \\ Coding Manual}

1. Make sure that you are calm and focused. If you feel foggy or rushed, do not attempt to code. Bad coding is worse than no coding. We will be doing reliability checks (recoding) on a randomly selected $20 \%$ of subjects and if coding is not reliable, we will have to recode everything. Read this entire manual before beginning coding.

2. Get the Infant, Parent, and Nurse Behaviors Coding Sheets and big videotape.

3. Write the Subject number, your initials, the date (from the recording), and the number of people being coded on the top of the sheets.

4. Cue the tape until you find where the nurse begins cleaning the child's skin for the injection. Write this time down on a scrap piece of paper because you will need it later.

5. Rewind the tape exactly 3 minutes from the beginning of the cleaning. That will be where you being coding. Round down to the nearest 5 seconds (e.g., If the time is $8: 45: 38$, rewind to $8: 45: 35$ ).

6. Write this time down on the first available spot on the Coding Sheets. In other words, if the time that you will start (i.e., 3 minutes prior to cleaning) is $8: 45: 35$, then fill in 8:45 to the left of ' $: 35$ ' on the Coding Sheets. You do not need to put 8:45 next to the following numbers, but do put the next minute down (i.e., 8:46 next to the ':00'). Cross through the blank part of the page above

7. From the beginning of coding until the cleaning of the child's skin is Phase 1 (remember I said in point 3 above to write the time down). Indicate this on the far left of the page by putting a 1 at the beginning time (i.e., 3 minutes prior to cleaning) and the ending time (i.e., cleaning of the skin).

8. Now you are set to begin coding. Focus on one participant at a time. In other words, if you want to code the child first, only code the child. Do not attempt to code the child, parent, and nurse simultaneously.

9. Watch the child's behavior, the running clock, and where you are on your page. This takes some practice and you will have to rewind several time when you first start coding.

10. Each time the child exhibits one of the coded behaviors, put a 1 on the sheet in the box corresponding to that code and the time interval (if it occurred at 9:15:28 it would go in the 9:15:25 box). 
11. If a behavior continues for more than 5 seconds, continue to code it for each interval that it occurs.

12. If you are unable to see the child, parent, or nurse, put a 1 in the Not Visible box on the correct sheet. If you are able to hear the child, parent, or nurse (e.g., crying, distracting comments, kiss), continue to code these behaviors. If you are able to make a good guess at the non-visible behavior (e.g., if the child is smiling before someone blocks the view of the child's face and the child is still smiling after the blocker is gone), code this too.

13. When the nurse removes the needle from the child for the last injection (this may include 1, 2, 3, or more injections), this indicates the end of Phase 2. Round up to the next 5-second block. Put a 2 to the left of that box and a 2 in the box following the indication of the end of Phase 1.

14. When the nurse withdraws the needle for the final injection, note that time on a scrap of paper. You will only code for 2 more minutes after that point or else until the child leaves the room, whichever comes first. This segment is Phase 3.

15. Once you have finished coding the child, transfer your time and phase indications to the parent and nurse sheets.

16. Now rewind the tape and code the parent and nurse behaviors.

17. When finished, indicate this on the signup sheets and put the coding sheets into the proper basket.

18. Relax and give yourself a pat on the back for a job well done.

Phases

1. Up to 3 minutes prior to the application of the alcohol or cleaning the infant's skin for the first injection.

2. From the cleaning of the skin for the first injection until the withdrawal of the needle for the final injection (this may include 1,2,3, or more injections).

3. From the withdrawal of the last injection until 2 minutes pass, the infant leaves the room, or taping ends, whichever comes first. 


\section{MAISD Coding Manual}

\begin{tabular}{|c|c|}
\hline $\begin{array}{l}\text { Adult } \\
\text { Category } \\
\end{array}$ & Definition and Examples \\
\hline Distraction & $\begin{array}{l}\text { Behaviors intended to distract the infant. This may include the use of props } \\
\text { (e.g., holding up toys, pointing to posters on the wall) or not (e.g., making } \\
\text { funny faces, clapping). This is still coded even if the child does not appear to be } \\
\text { distracted by the behavior. }\end{array}$ \\
\hline Offer Toy & $\begin{array}{l}\text { If the adult simply hands the child a toy-like object in an effort to comfort or } \\
\text { distract him/her. If the parent uses the toy to interact with the child, code } \\
\text { Distraction and not Offer Toy. Often an adult may hand the child a toy so that } \\
\text { the child will soothe him/herself. }\end{array}$ \\
\hline Offer Pacifier & $\begin{array}{l}\text { If the parent either hands the infant the pacifier or puts the pacifier in the } \\
\text { infant's mouth. This is still coded if the infant does not accept the pacifier. }\end{array}$ \\
\hline Offer Food & $\begin{array}{l}\text { Feeding can include handing the child a bottle, cracker, or other food. Code } \\
\text { even if the child rejects the food. Do not code this if the mother attempts to or } \\
\text { is nursing the child. }\end{array}$ \\
\hline $\begin{array}{l}\text { Attempt to } \\
\text { nurse }\end{array}$ & Attempts to nurse or actually engaging in nursing. \\
\hline Tickle & $\begin{array}{l}\text { Purposeful tickling of the child in order to produce laughter. The child does not } \\
\text { have to laugh or squirm. }\end{array}$ \\
\hline $\begin{array}{l}\text { Rub/ } \\
\text { Massage/ } \\
\text { Pat }\end{array}$ & $\begin{array}{l}\text { Rubbing, massaging, or patting the child. This may be on the head, back, or } \\
\text { other body part. This is often intended to distract and/or comfort the child. }\end{array}$ \\
\hline Kiss & Kissing the child. \\
\hline Hug & $\begin{array}{l}\text { A comforting hug. If the adult is simply holding the child so that the procedure } \\
\text { may be performed, do not code hug. This has to be an obvious and blatant } \\
\text { squeeze. }\end{array}$ \\
\hline Sitting Rock & $\begin{array}{l}\text { If the parent remains in the chair and begins to sway, rock, or bounce the child. } \\
\text { Code Standing Rock if the parent stands up and/or walks. }\end{array}$ \\
\hline $\begin{array}{l}\text { Standing } \\
\text { Rock }\end{array}$ & $\begin{array}{l}\text { When the adult stands up and rocks, sways, or bounces, or when the adult } \\
\text { moves around the room while holding the child. }\end{array}$ \\
\hline $\begin{array}{l}\text { Verbal } \\
\text { Reassurance }\end{array}$ & $\begin{array}{l}\text { You may still be able to code things that you can hear (e.g., Verbal } \\
\text { Reassurance) and if you have a good guess at a behavior. For example, if the } \\
\text { adult is frowning, then turns his/her back to the camera, and then turns around } \\
\text { again and is still frowning, you can guess that he/she continued to frown when } \\
\text { not visible. }\end{array}$ \\
\hline Not Visible & Code if the adult is not visible. \\
\hline
\end{tabular}




\begin{tabular}{|c|c|}
\hline Infant Category & Definitions and examples \\
\hline Engage in Distraction & $\begin{array}{l}\text { Watches distraction (e.g., toys, posters on the wall, television, funny faces, } \\
\text { clapping) or interacts with parent on non-procedural event (e.g., playing with } \\
\text { toy, playing peek-a-boo). }\end{array}$ \\
\hline $\begin{array}{l}\text { Play with Object } \\
\text { Alone }\end{array}$ & $\begin{array}{l}\text { Manipulating, moving, or playing with a toy or object of interest (e.g., stuffed } \\
\text { animal, sock, keys, bottle, piece of plastic). However, he/she must play by } \\
\text { his/herself otherwise code as Engage in Distraction. This may be interpreted as } \\
\text { self-soothing rather than relying on adult-soothing, even if adult gives child the } \\
\text { object. }\end{array}$ \\
\hline Suck on Pacifier & $\begin{array}{l}\text { If the pacifier is in the infant's mouth at all, even if you can not see sucking } \\
\text { action, code this. }\end{array}$ \\
\hline Consume Food & Drinking from a bottle or eating solids (e.g., crackers, baby food). \\
\hline Nursing & $\begin{array}{l}\text { Attempts to breast-feed (e.g., pulling on mom's blouse, says "nurse") or } \\
\text { actually engaging in nursing. }\end{array}$ \\
\hline Happy Behavior & Smiling, cooing. \\
\hline Laugh & Laughing. \\
\hline Negative Behavior & $\begin{array}{l}\text { Furrowed brow, eyes closed tightly, open lips. Negative whining/complaining } \\
\text { sounds. If the baby is just making typical baby squeaks and other noises, only } \\
\text { code if the noise appears to be a distress/negative sound. }\end{array}$ \\
\hline Cry & Sobbing or full-lunged cry. \\
\hline Scream & High-pitched yell. \\
\hline Flail & $\begin{array}{l}\text { Complex, agitated body movements. If child is being restrained, look for body } \\
\text { tension and squirming. If the child is simply wiggling around, do not code this } \\
\text { as flail. Flail is a distress behavior. }\end{array}$ \\
\hline
\end{tabular}




\section{CATHERINE BRADFORD MCCLELLAN}

\section{Curriculum Vitae}

$\begin{array}{ll}\text { Work Address: } & \begin{array}{l}\text { Department of Psychology } \\ \text { West Virginia University } \\ \text { Morgantown, West Virginia, 26505 }\end{array} \\ \text { Home Address: } & \begin{array}{l}\text { 1220 Lions Ave. } \\ \text { Morgantown, WV 26505 }\end{array} \\ \text { E-mail Address: } & \text { cbmcclellan @earthlink.net } \\ \text { Telephone: } & \\ \text { Work: } & \text { (304) } 293-2001 \text { ext. } 857 \\ \text { Home: } & \text { (304) } 599-2698\end{array}$

Graduate:

\section{EDUCATION AND TRAINING}

Clinical Psychology Doctoral student, West Virginia University, Morgantown, West Virginia $(8 / 00$ - present $)$

Clinical Psychology Doctoral student, Washington State University, Pullman, Washington $(8 / 99-7 / 00)$

\section{Undergraduate:}

B.A., Psychology, Reed College, Portland, Oregon (5/97).

Commendation for Excellence for academic year of 1996-1997. Undergraduate thesis "Differences in Factors Associated with Popular Status and Regular Status Children"

\section{PROFESSIONAL AFFILIATIONS}

Society of Pediatric Psychology (9/99 - present)

Association for Advancement of Behavior Therapy (3/00 - present)

American Psychological Association (8/00 - present, number 42861389 AMP V56\#01 V56\#08) 


\section{RESEARCH EXPERIENCE}

Graduate Research Assistant, Health Behaviors Research Center. (7/01-present)

Aided in various aspects of grant preparation, data management, and analysis for a variety of pediatric psychology research programs, including research on pediatric oncology, Neurofibromatosis, and Cystic Fibrosis. SupervisorsL Dr. Drew Bradlyn and Dr. Carole Harris.

Graduate Research Assistant, “A Critical Time to Intervene: A Longitudinal Study of Infant's Fear, Anxiety, and Pain During Immunizations." (8/99-8/00)

Study of infant pain and distress during immunization procedures. Duties included coordinating research assistants, obtaining physiological measures of infant and parent distress, applying topical anesthesia (EMLA), supervising data management and coding. Supervisor: Dr. Lindsey Cohen.

Research Assistant, "Study of Chronic Pain Management" (7/97 - 7/99)

Study of pain in persons with Amputations, Spinal Cord Injuries, and Cerebral Palsy. Duties included serving as liaison for the Spinal Cord Injury group; interviewing drug study participants; conducting measures of pain intensity, psychological, and physiological functioning; conducting analyses with SPSS; developing methods to obtain improved response rates, and aiding in the development of revised "Survey of Pain Characteristics in Persons with Spinal Cord Injury." Supervisor: Dr. Mark Jensen.

Research Assistant, "University of Washington Physician Referral Study” (6/97 - 10/97)

Developed coding protocols and coded questionnaires investigating the frequency of health insurance plans in referring patients with pain and or depression to specialists. Supervisor: Deborah Dickestein.

Research Assistant, "The Development of Coping with Angry Provocation" (5/95 - 5/97)

Examined factors that influence children's responses to a provoking peer. Collected sociometric data for classes of children in the second, forth, and sixth grades. Coded children's responses to provocation by a confederate child. Supervisor: Dr. Marion Underwood.

Investigator, "Differences in Factors Associated with Popular Status and Regular Status Children" (9/96 - 5/97)

Designed and conducted yearlong independent research project. This thesis project included literature review, research design, recruiting participants, interviewing 50 ten to twelve year old children, and data analysis. Supervisor: Dr. Marion Underwood. 


\section{PUBLICATIONS}

Cohen, L. L., Blount, R. L., Cohen, R. J., Ball, C. M., McClellan, C. B., \& Bernard, R. S. (2001). Children's expectations and memories of acute distress: The short- and long-term efficacy of pain management interventions. Journal of Pediatric Psychology, 26 (6), 367-374.

\section{POSTER PRESENTATIONS}

Cohen, L.L., Bernard, R.S., \& McClellan, C.B. (February, 2001). Assessment of children's approach-avoidance behavior during immunizations: A comparison of ratings and observations. Invited poster presented at the American Association for Dental Research, Morgantown, WV.

Cohen, L. L., McClellan, C.B., \& Bernard, R. S. (November 2000). The impact of nurse-directed distraction on infant immunization distress. Poster presented at AABT Convention, New Orleans.

Cohen, L. L., Bernard, R. S., \& McClellan, C. B. (November 2000). Assessment of children's approach-avoidance behavior during immunizations: A comparison of ratings and observations. Poster presented at AABT Convention, New Orleans.

Warms, C.A., Cardenas, D.D., Turner, J.A., \& McClellan, C.B. (November 1999). Spinal cord injury related chronic pain: Scope of the problem and helpfulness of treatments. Poster presented at the Association of Rehabilitation Nurses, 25th Annual Conference, Minneapolis.

Turner, J.A., Cardenas, D.D., Warms, C.A., \& McClellan, C.B. (August 1999). The role of catastrophizing in emotional distress and pain-related activity interference in individuals with spinal cord injury (SCI) pain. Poster presented at the Conference of the $9^{\text {th }}$ World Congress on Pain, Vienna. 
Cohen, L. L., Bernard, R.B., \& McClellan, C.B. (November 2001). Pediatric procedural approach-avoidance coping and distress: A multitrait-multimethod assessment. Poster submitted for the AABT Convention, Philadelphia.

Cohen, L.L., McClellan, C.B., \& Bernard, R.S. (November 2001). Practical behavioral interventions for infant procedural distress. Poster submitted for the AABT Convention, Philadelphia.

Cohen, L. L., Bernard, R. S., \& McClellan, C. B. (April, 2001). Preschoolers self-report of procedural approach-avoidance. Poster presented at the Florida Conference on Child Health Psychology, Gainesville, Florida.

Cohen, L. L., McClellan, C. B., \& Bernard, R. S. (April, 2001). Infant distress by procedural phase. Poster presented at the Florida Conference on Child Health Psychology, Gainesville, Florida.

Ware, L.M., McClellan, C.B., Vincent, J. D., Triplett, H., \& McNeil, C.B. (June, 2001). Assessment guiding treatment in parent child interaction therapy: A clinical care presentation of oppositional defiant disorder with pervasive developmental disorder not otherwise specified. Poster presented at the Annual Parent-Child Interaction Therapy Conference, Sacramento, California.

\section{INVITED SYMPOSIA/ORAL PRESENTATIONS}

Cohen, L. L., Blount, R. L., Cohen, R. J., Ball, C. M., McClellan, C. B., \& Bernard, R. S. (August, 2001). Painful medical procedures as trauma: How deep do the wounds go? In J. Faust (Chair) \& L. J. Siegel (Discussant), Trauma and Children in Health Care Settings. Symposium presented at the APA conference, Washington, D.C. 
Cohen, L. L., Blount, R. L., Cohen, R. J., McClellan, C. B., Bernard, R. S., \& Ball, C. M. (August, 2000). Children's expectations and memories of acute medical distress. In D. Drotar (Chair) \& D. Faust (Discussant), Prevention and Early Intervention in Primary Care Contexts. Symposium presented at the APA conference, Washington, D.C.

\section{REVIEWING ACTIVITY}

Reviewed manuscript for Children's Health Care, January, 2001 with Lindsey Cohen, Ph.D.

Reviewed manuscript for Children's Health Care, April 2001 with Lindsey Cohen, Ph.D.

Reviewed manuscript for Children's Health Care, August 2001 with Lindsey Cohen, Ph.D.

\section{CLINICAL EXPERINCE}

Pediatric Psychology Training Practicum, West Virginia University (8/01-present)

Conducted individual counseling with children and adolescents presenting with chronic illnesses (IBS ...) and difficulties associated with these illnesses. Supervisor: Dr. Christina Adams.

Parent-Child Interaction Training Practicum, West Virginia University (8/00-7/01)

Trained parents to employ behavioral modification techniques with their behaviorally disordered children. Supervisor: Dr. Cheryl McNeil.

Learning Disabilities Practicum, Washington State University (1/00 - 7/00)

Conducted learning disability evaluations using standardized assessment measures on clients presenting to the psychology clinic. Supervisor: Dr. Maureen Schmitter-Edgecombe

Child Development Rehabilitation Center, Oregon Health Sciences University (1/96 - 12/96) 
Worked in an integrated preschool for children with and without pervasive developmental disorders such as autism, developmental delays, and failure to thrive. Responsibilities included engaging children in productive activities and eliciting speech from non-verbal children.

\section{TEACHING EXPERIENCE}

Research Methods, West Virginia University, (8/00- present)

Taught three sections of a junior and senior level class. Responsible for preparing and delivering lectures, examinations, and grading APA style research projects.

Principles of Development, Washington State University (8/99-12/99)

Teaching assistant for Dr. Lindsey Cohen. Responsibilities included correcting term papers, other assignments, and occasional lecturing,

\section{REFERENCES AVAILABLE UPON REQUEST}

